\title{
Catalytic Reactions of Guaiacol: Reaction Network and Evidence of Oxygen Removal in Reactions with Hydrogen
}

\author{
Tarit Nimmanwudipong • Ron C. Runnebaum • \\ David E. Block • Bruce C. Gates
}

Received: 17 December 2010/ Accepted: 2 March 2011/Published online: 30 March 2011

(c) The Author(s) 2011. This article is published with open access at Springerlink.com

\begin{abstract}
The conversion of guaiacol, a prototypical compound representative of lignin-derived pyrolysis biooils, was catalyzed by $\mathrm{Pt} / \mathrm{Al}_{2} \mathrm{O}_{3}$ in the presence of $\mathrm{H}_{2}$ at $573 \mathrm{~K}$. The conversion took place with a high selectivity for aromatic carbon-oxygen bond cleavage relative to the accompanying methyl group transfer reactions. This oxygen removal was not observed in the absence of $\mathrm{H}_{2}$ as a coreactant. Products that were formed by methyl-group transfer match those produced in the conversion catalyzed by zeolite HY, which was not active for oxygen removal reactions.
\end{abstract}

Keywords Guaiacol - Supported platinum - Zeolite Y . Transalkylation · Hydrodeoxygenation

\section{Introduction}

Lignin constitutes as much as $30 \mathrm{wt} \%$ of lignocellulosic biomass [1,2] and offers excellent potential as a feedstock for conversion to fuels and chemicals by pyrolysis, giving "bio-oils." The results of earlier investigations [3-7] show that catalytic upgrading can be used to remove oxygen

T. Nimmanwudipong $\cdot$ R. C. Runnebaum .

D. E. Block · B. C. Gates ( $\triangle)$

Department of Chemical Engineering and Materials Science,

University of California, Davis, CA 95616, USA

e-mail: bcgates@ucdavis.edu

D. E. Block

Department of Viticulture and Enology, University of California,

Davis, CA 95616, USA from these liquids to minimize the instability and corrosion issues. In comparison with the widely investigated cellulose-derived components of bio-oils (including carbohydrates) [8-10], the lignin-derived components have lacked attention, and there is limited understanding of the reaction networks and kinetics [11-13]. Our approach was to begin investigating the reaction network for a characteristic lignin-derived compound found in pyrolysis bio-oils-guaiacol. A specific goal was to elucidate the oxygen-removal reactions in the conversion in the presence of an important class of catalysts: a metal dispersed on an acidic support $\left(\mathrm{Pt} / \mathrm{Al}_{2} \mathrm{O}_{3}\right)$. Data were also collected with a solid acid catalyst (zeolite $\mathrm{HY}$ ) to identify the reactions catalyzed by an acidic function (such as the $\mathrm{Al}_{2} \mathrm{O}_{3}$ support) and distinguish them from the reactions catalyzed by the metal.

\section{Experimental}

Powders of $\mathrm{Pt} / \mathrm{Al}_{2} \mathrm{O}_{3}$ (1 wt\% Pt, Sigma-Aldrich) and zeolite HY (Zeolyst CBV 720) were pre-treated in flowing streams of $\mathrm{H}_{2} / \mathrm{N}_{2}$ and $\mathrm{N}_{2}$, respectively, at $573 \mathrm{~K}$. Catalytic reactions were conducted in a once-through packed-bed flow reactor under the following conditions, with liquid reactant (99.5 wt\% guaiacol) vaporized into a flowing gas stream $\left(30 \% \mathrm{H}_{2} / 70 \% \mathrm{~N}_{2}\right.$ in experiments with $\mathrm{Pt} / \mathrm{Al}_{2} \mathrm{O}_{3}$ and $\mathrm{N}_{2}$ in experiments with $\mathrm{HY}$ zeolite): catalyst mass, $0.010-0.100 \mathrm{~g}$ (catalyst diluted with particles of inert, nonporous $\alpha-\mathrm{Al}_{2} \mathrm{O}_{3}$ ); temperature, $573 \mathrm{~K}$; pressure, $140 \mathrm{kPa}$; liquid reactant feed rate, $0.015 \mathrm{~mL} / \mathrm{min}$; and gas feed flow rate, $100 \mathrm{~mL} / \mathrm{min}$. The product gas stream was condensed at 285-288 K. Uncondensed gases and condensate samples collected periodically were analyzed by gas chromatography and gas chromatography/mass spectrometry. 


\section{Results}

Dozens of products were detected and identified in the reactions observed with each catalyst. As in recent work on anisole [14], more rapid catalyst deactivation was observed with the zeolite ( $\sim 50 \%$ reduction in conversion within $1 \mathrm{~h}$ on stream) than with the $\mathrm{Pt} / \mathrm{Al}_{2} \mathrm{O}_{3}$ catalyst operating in the presence of $\mathrm{H}_{2}$ (Fig. 1). Selectivities to the most abundant products formed at low initial conversions ( 0.08 for $\mathrm{Pt} / \mathrm{Al}_{2} \mathrm{O}_{3}$ and 0.11 for $\mathrm{HY}$ zeolite) are summarized in Table 1. Initial conversions, obtained by extrapolating conversion data to zero time on stream, were used to determine catalyst activities in the absence of catalyst deactivation. Because the conditions were chosen to allow determination of initial catalyst performance, only minimal amounts of coke were formed in our experiments; the changes in mass of our packed beds containing catalyst in the various experiments were less than $0.1 \%$.

The predominant products of the reactions catalyzed by $\mathrm{Pt} / \mathrm{Al}_{2} \mathrm{O}_{3}$ were phenol, benzene-1,2-diol (catechol), and 3-methylbenzene-1,2-diol (3-methylcatechol); less abundant products were water, methane, methanol, benzene, toluene, anisole, cyclohexanone, 2-methylphenol (o-cresol), 2-methoxy-3-methylphenol (3-methylguaiacol), 6-methylguaiacol, and 1,2-dimethoxybenzene. Several trace products were also detected, including cyclohexane, cyclohexene, methoxycyclohexane, xylenes, cyclohexanol, methylcyclohexanones, methylanisoles, 4-methylguaiacol, 5-methylguaiacol, dimethylphenols, trimethylphenols, tetramethylphenols, and dimethylhydroquinones. These products were presumably

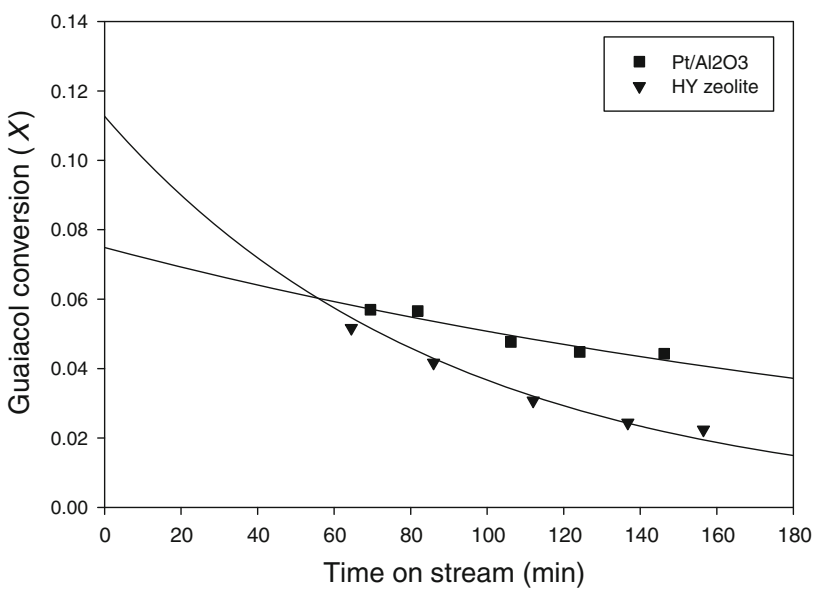

Fig. 1 Conversion of guaiacol catalyzed by $\mathrm{HY}$ zeolite and by $\mathrm{Pt} / \mathrm{Al}_{2} \mathrm{O}_{3}$ at $573 \mathrm{~K}, 140 \mathrm{kPa}$, and $100 \mathrm{~mL} / \mathrm{min}$ gas feed flow rate $\left(30 \% \mathrm{H}_{2} / 70 \% \mathrm{~N}_{2}\right.$ in experiments with $\mathrm{Pt} / \mathrm{Al}_{2} \mathrm{O}_{3}$ and $\mathrm{N}_{2}$ in experiments with HY zeolite). Weight hourly space velocity (WHSV) $=20$ $(\mathrm{g}$ reactant $) /(\mathrm{g}$ catalyst $\times \mathrm{h})$

formed by hydrogenation, methyl group transfer (transalkylation, which could be intra- or intermolecular) and isomerization reactions.

In contrast, none of the deoxygenated products such as anisole and phenol was observed in the reactions catalyzed by the zeolite. The most abundant products observed with this catalyst were catechol, 1,2-dimethoxybenzene, 3-methylguaiacol, 4-methylguaiacol, 5-methylguaiacol, and 6-methylguaiacol; a less abundant product was 3-methylcatechol. Trace products included dimethoxytoluenes,

Table 1 Products of conversion of guaiacol catalyzed by $\mathrm{Pt} / \mathrm{Al}_{2} \mathrm{O}_{3}$ and by $\mathrm{HY}$ zeolite (liquid product streams)

\begin{tabular}{|c|c|c|c|}
\hline Product & $\begin{array}{l}\text { Selectivity to product in reaction } \\
\text { catalyzed by } \mathrm{Pt} / \mathrm{Al}_{2} \mathrm{O}_{3} \text { with } \mathrm{H}_{2}{ }^{\mathrm{a}}\end{array}$ & $\begin{array}{l}\text { Selectivity to product in reaction } \\
\text { catalyzed by HY zeolite }^{b}\end{array}$ & $\begin{array}{l}\text { Selectivity to product in reaction } \\
\text { catalyzed by } \mathrm{Pt} / \mathrm{Al}_{2} \mathrm{O}_{3} \text { without } \mathrm{H}_{2}{ }^{\mathrm{b}}\end{array}$ \\
\hline Benzene & 0.002 & - & - \\
\hline Toluene & 0.0004 & - & - \\
\hline Anisole & 0.009 & - & - \\
\hline Cyclohexanone & 0.026 & - & - \\
\hline Phenol & 0.316 & - & - \\
\hline$o$-Cresol & 0.031 & - & - \\
\hline 1,2-Dimethoxybenzene & 0.021 & 0.300 & 0.242 \\
\hline 3-Methylguaiacol & 0.012 & 0.015 & 0.031 \\
\hline 4-Methylguaiacol & Trace & 0.071 & Trace \\
\hline 5-Methylguaiacol & Trace & 0.043 & Trace \\
\hline 6-Methylguaiacol & 0.031 & 0.049 & 0.105 \\
\hline Catechol & 0.412 & 0.49 & 0.560 \\
\hline 3-Methylcatechol & 0.125 & 0.032 & 0.055 \\
\hline
\end{tabular}

Data were extrapolated to zero time on stream, and thus represent approximate initial selectivities determined at a weight hourly space velocity of 20 (g of reactant $) /(\mathrm{g}$ of catalyst $\cdot \mathrm{h}$ ), a pressure of $140 \mathrm{kPa}$, and a temperature of $573 \mathrm{~K}$. Selectivity is defined as yield [mol product formed/mol of organic reactant fed]/conversion [mol of organic reactant consumed/mol of organic reactant fed]

a $100 \mathrm{~mL} / \mathrm{min}$ gas feed rate, $30 \% \mathrm{H}_{2} / 70 \% \mathrm{~N}_{2}$; feed molar ratio of $\mathrm{H}_{2}$ to the organic reactant was 10

b $100 \mathrm{~mL} / \mathrm{min}$ gas feed rate, $100 \% \mathrm{~N}_{2}$ 


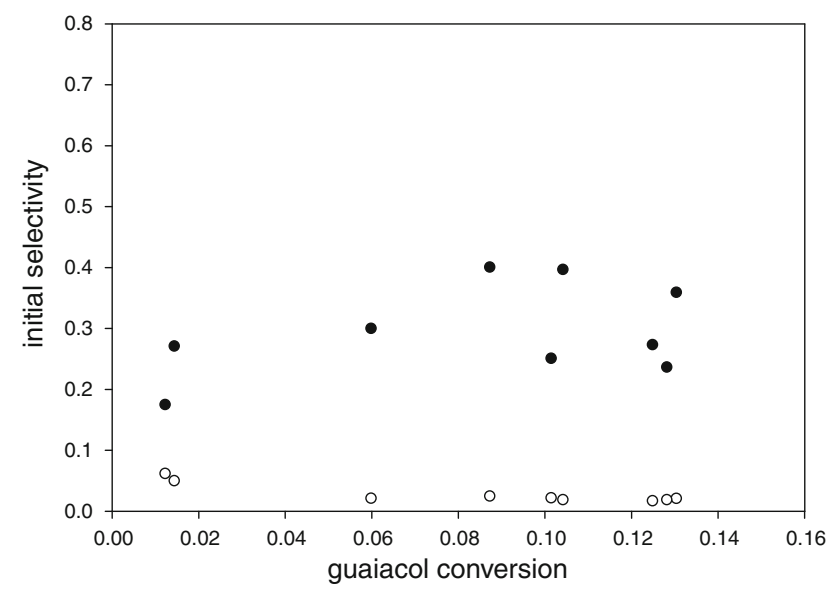

Fig. 2 Selectivity for the formation of phenol (closed circles) and 1,2dimethoxybenzene (open circles) in the conversion of guaiacol catalyzed by $\mathrm{Pt} / \mathrm{Al}_{2} \mathrm{O}_{3}$ in the presence of $\mathrm{H}_{2}$ at $573 \mathrm{~K}$. Data for each product were fitted with a straight line and extrapolated to zero conversion; intercepts of regression lines significantly different from zero selectivity at zero conversion (analyzed with $95 \%$ confidence limits) indicate primary products, both phenol and 1,2-dimethoxybenzene

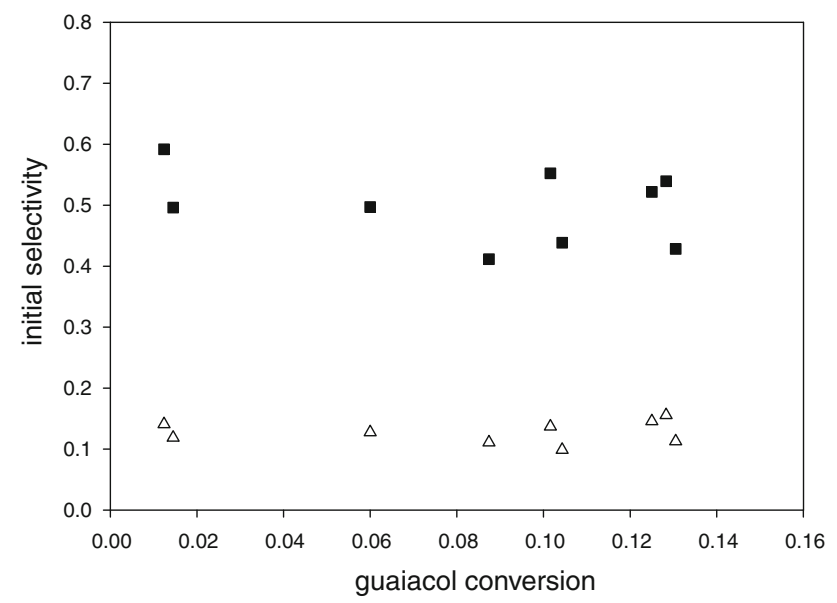

Fig. 3 Selectivity for the formation of catechol (squares) and 3 -methylcatechol (triangles) in the conversion of guaiacol catalyzed by $\mathrm{Pt} / \mathrm{Al}_{2} \mathrm{O}_{3}$; conditions are stated in the text. Data for each product were fitted with a straight line and extrapolated to zero conversion; intercepts of regression lines significantly different from zero selectivity at zero conversion (analyzed with $95 \%$ confidence limits) indicate primary products, both catechol and 3-methylcatechol

4-methylcatechol, dimethylphenols, trimethylphenols, and tetramethylphenols. The traces of alkylated phenols were possibly produced from the impurity phenol in the feed guaiacol.

These data show that methyl-group transfer is an important class of reaction observed for both catalysts. Reactions with $\mathrm{H}_{2}$ leading to oxygen removal as water or methanol (hydrodeoxygenation) and hydrogenation, on the other hand, were kinetically significant only with the $\mathrm{Pt} /$ $\mathrm{Al}_{2} \mathrm{O}_{3}$ catalyst used in the presence of $\mathrm{H}_{2}$. In the absence of

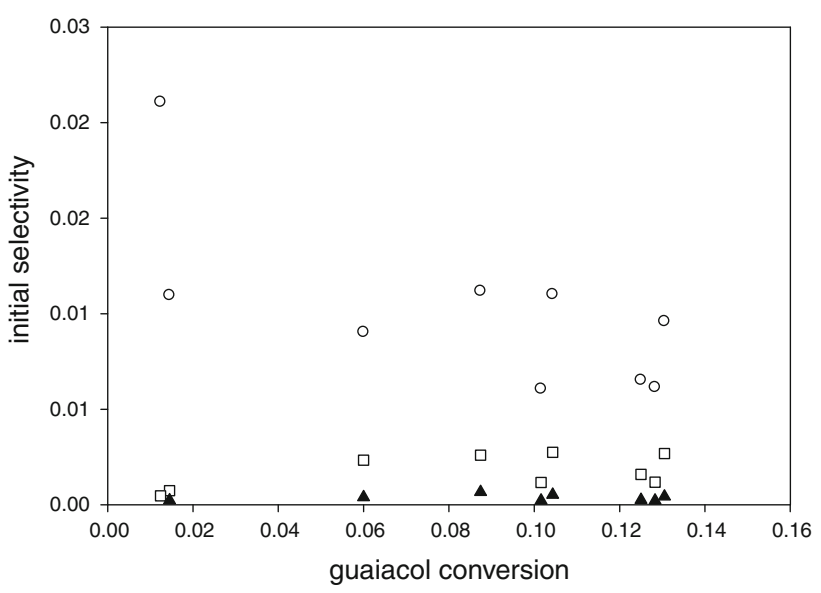

Fig. 4 Selectivity for the formation of anisole (circles), benzene (squares), and toluene (triangles) in the conversion of guaiacol catalyzed by $\mathrm{Pt} / \mathrm{Al}_{2} \mathrm{O}_{3}$; conditions are stated in the text. Data for each product were fitted with a straight line and extrapolated to zero conversion; intercepts significantly different from zero selectivity at zero conversion (analyzed with 95\% confidence limits) indicate primary products, in this case anisole, and those not significantly different from zero (analyzed with 95\% confidence limits) are considered to be evidence of non-primary products, both benzene and toluene

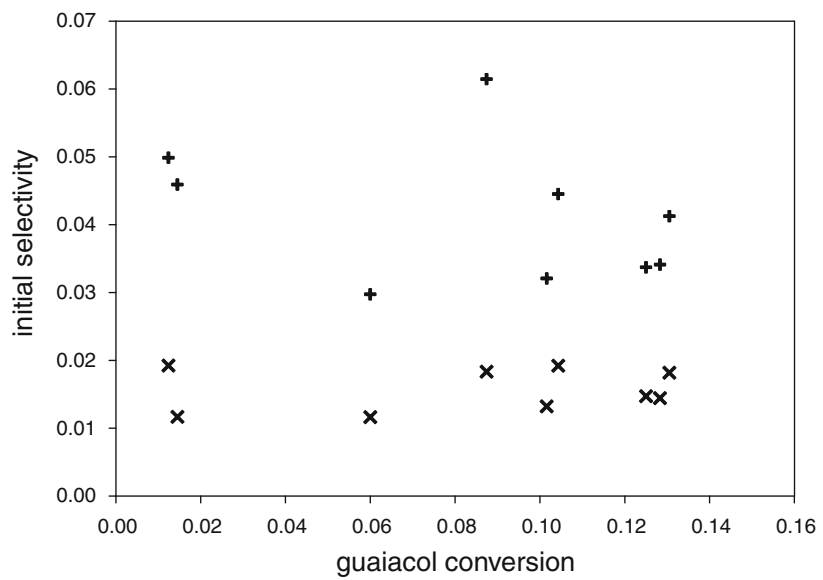

Fig. 5 Selectivity for the formation of 3-methylguaiacol (times) and 6-methylguaiacol (plus) in the conversion of guaiacol catalyzed by Pt/ $\mathrm{Al}_{2} \mathrm{O}_{3}$; conditions are stated in the text. Data for each product were fitted with a straight line and extrapolated to zero conversion; intercepts significantly different from zero selectivity at zero conversion (analyzed with $95 \%$ confidence limits) indicate primary products, both 3-methylguaiacol and 6-methylguaiacol

$\mathrm{H}_{2}$, the conversion in the presence of this catalyst was nearly zero $(<0.01$ under our conditions, data not shown), and no deoxygenated products were observed. Then, as shown in Table 1, only products similar to those formed with the HY zeolite catalyst were observed.

To determine an approximate reaction network for the conversion of guaiacol catalyzed by $\mathrm{Pt} / \mathrm{Al}_{2} \mathrm{O}_{3}$ in the presence of $\mathrm{H}_{2}$, selectivity versus conversion plots (e.g., Fig. 2) 


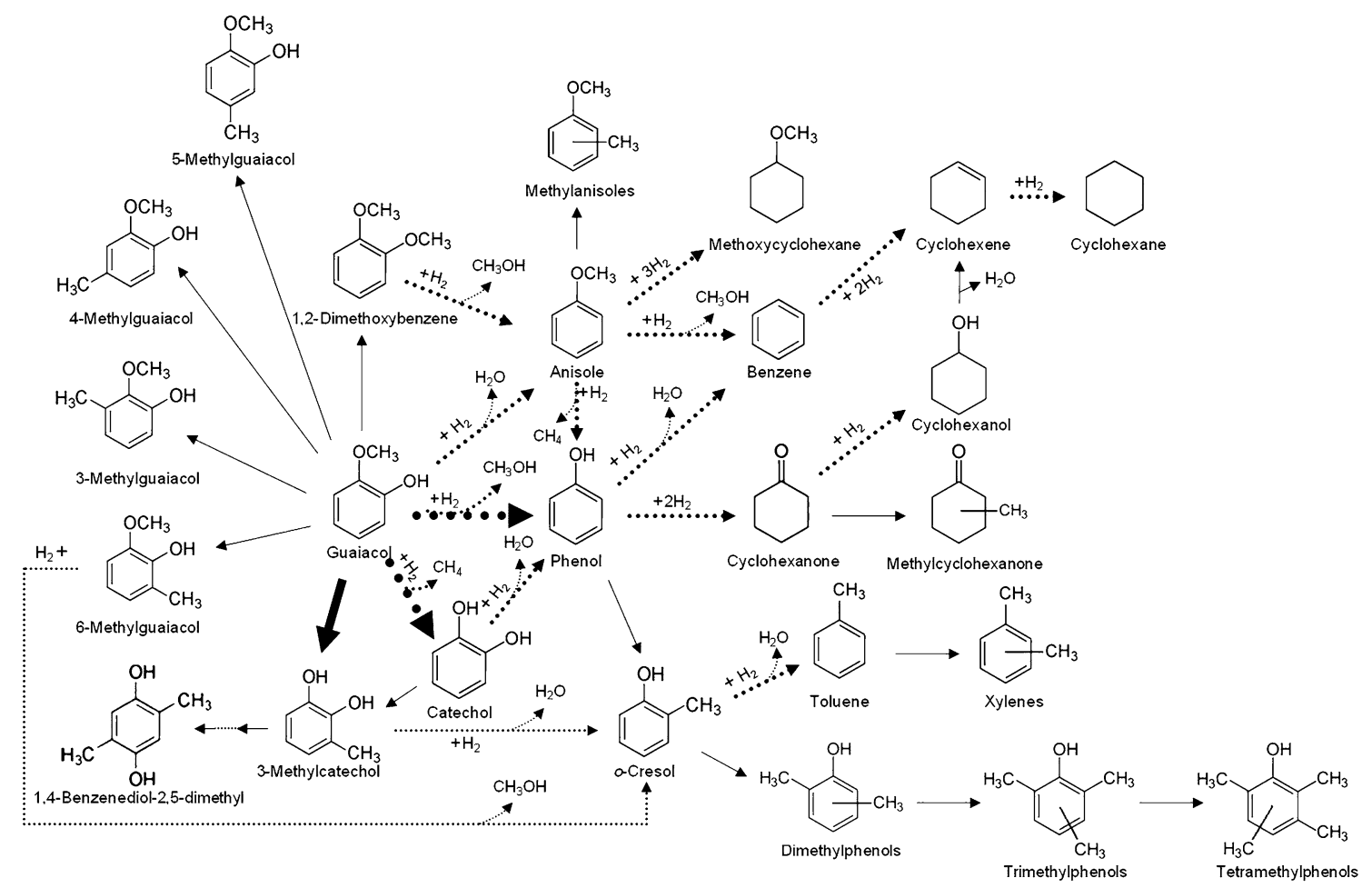

Fig. 6 Reaction network for the conversion of guaiacol and hydrogen catalyzed by $\mathrm{Pt} / \mathrm{Al}_{2} \mathrm{O}_{3}$ at $573 \mathrm{~K}$. Reactions are postulated on the basis of the products identified, including trace compounds, and their formation as a result of the likely reaction classes identified in the text. Hydrogenation/hydrogenolysis/hydrodeoxygenation reactions

were used to identify products as primary or not $[15,16]$ (these designations are empirical, falling short, for example, of providing information about intermediates that were too reactive to be detected).

The selectivity-conversion data observed for guaiacol conversion catalyzed by $\mathrm{Pt}_{2} \mathrm{Al}_{2} \mathrm{O}_{3}$ (Figs. $2,3,4,5$ ) in the presence of $\mathrm{H}_{2}$ indicate that anisole, phenol, catechol, 3-methylcatechol, 3-methylguaiacol, 6-methylguaiacol, and 1,2-dimethoxybenzene were primary products, whereas benzene, toluene, cyclohexanone (data not shown), and $o$-cresol (data not shown) were non-primary products.

Presuming that transalkylation, hydrodeoxygenation, and hydrogenation are the important reaction classes, by recognizing which compounds were primary and which were non-primary products, and by using our chemical judgment of the most likely classes of reaction for formation of minor and trace products, we inferred the reaction network of Fig. 6 for guaiacol conversion catalyzed by $\mathrm{Pt} / \mathrm{Al}_{2} \mathrm{O}_{3}$ in the presence of $\mathrm{H}_{2}$.

\section{Discussion}

The reaction network of Fig. 6 accounts for major, minor, and trace products in the reactions catalyzed by $\mathrm{Pt} / \mathrm{Al}_{2} \mathrm{O}_{3}$; it are represented by dotted arrows and methyl group transfer/dehydration reactions by solid arrows. Organic coreactants are omitted for simplicity. Bold arrows show the reactions that are kinetically most significant

contains more detail than previously reported reaction networks proposed for the conversion of guaiacol catalyzed by platinum or other supported metals. In most of these reports, no reaction networks were presented; the catalysts were $\mathrm{Ru} / \mathrm{C}$ [17], $\mathrm{Pd} / \mathrm{C}$ [17], $\mathrm{Pt} / \mathrm{ZrO}_{2}$ [18], and $\mathrm{V} / \mathrm{Al}_{2} \mathrm{O}_{3}$ [19].

Our results are broadly consistent with these reports in terms of the classes of reactions observed, but different products are reported in our work because of the different catalysts and operating conditions. In the comparable work with the $\mathrm{Pt} / \mathrm{ZrO}_{2}$ catalyst [18], the reported products not observed in our work include 2-methoxycyclohexanone, 1-methyl-1,2-cyclohexanediol, and 1,2-dimethoxycyclohexane; we suggest that the differences are associated with the higher pressure ( $8 \mathrm{MPa}$ ) and the higher $\mathrm{H}_{2}$ to guaiacol molar feed ratio $(\sim 25: 1)$ in the reported work.

In the reactions catalyzed by $\mathrm{Pt} / \mathrm{Al}_{2} \mathrm{O}_{3}$, anisole and phenol were formed as primary products, presumably by hydrodeoxygenation as the $\mathrm{C}-\mathrm{O}$ bond $\alpha$ to the aromatic ring in guaiacol was broken. Higher selectivity for phenol formation implies that deoxygenation by removal of the methoxy group is more favorable than deoxygenation by removal of the hydroxyl group. The reaction network also suggests that unimolecular and bimolecular transalkylation reactions occur in parallel-as 3-methylcatechol and 
methylguaiacols are both primary products. These methylgroup transfers likely take place on the slightly acidic $\mathrm{Al}_{2} \mathrm{O}_{3}$ support. In the methylation of guaiacol, only 3-methylguaiacol and 6-methylguaiacol were formed in substantial yields (4-methylguaiacol and 5-methylguaiacol were observed only as trace products). We suggest that the high selectivites for the former products may indicate that guaiacol interacts with the $\mathrm{Al}_{2} \mathrm{O}_{3}$ support through the methoxy or hydroxy group to form methoxyphenate and hydroxyphenate species, respectively [20], facilitating methylation preferentially at the position next to these groups and leading to the formation of 3-methylguaiacol and 6-methylguaiacol.

Consistent with recent reports [11, 21], cyclohexanone was observed as a partially hydrogenated product of phenol conversion. Without $\mathrm{H}_{2}$ in the feed, hydrodeoxygenation and hydrogenation routes, shown by the dotted lines in Fig. 6, were evidently minimized. The results emphasize the significance of $\mathrm{H}_{2}$ for oxygen removal from aromatic oxygenates (such as guaiacol, phenol, and anisole) and suggest the need for high $\mathrm{H}_{2}$ partial pressures in practical processes for processing of lignin-derived liquids.

Lacking the metal function, the HY zeolite catalyzed transalkylation as the only kinetically significant reactions, leading to products similar to those observed in the conversion catalyzed by the $\mathrm{Pt} / \mathrm{Al}_{2} \mathrm{O}_{3}$ in the absence of $\mathrm{H}_{2}$. This result is consistent with a report of the conversion of anisole catalyzed by HZSM-5 [13], and it highlights the importance of a metal function to catalyze hydrodeoxygenation.

\section{Conclusions}

The catalytic conversion of guaiacol catalyzed by $\mathrm{Pt} / \mathrm{Al}_{2} \mathrm{O}_{3}$ in the presence of $\mathrm{H}_{2}$ involves three major classes of reactions: hydrodeoxygenation, hydrogenation, and transalkylation. Selectivities to hydrodeoxygenation products were found to be comparable to selectivities to the accompanying transalkylation products. The acidic HY zeolite is not active for oxygen removal reactions. The data presented here provide a step towards predicting the conversion of lignin-derived bio-oils for removal of oxygen and upgrading of fuels.
Acknowledgments We thank Jennifer Heelan for advice on gas chromatography and Ryan Limbo, Kevin Tay, and Jonathan Doan for help with the experiments. Financial support for this work was provided by Chevron Technology Ventures, a division of Chevron USA, Inc. An Agilent Technologies Foundation Research Project Gift provided a GC7890 Refinery Gas Analyzer. Tarit Nimmanwudipong acknowledges a Fulbright Open Competition Scholarship.

Open Access This article is distributed under the terms of the Creative Commons Attribution Noncommercial License which permits any noncommercial use, distribution, and reproduction in any medium, provided the original author(s) and source are credited.

\section{References}

1. Stöcker S (2008) Angew Chem Int Ed Engl 47:9200

2. Milne T, Agblevor F, Davis M, Deutch S, Johnson D (1997) In: Bridgwater AV, Boocock DGB (eds) Developments in Thermal Biomass Conversion. Blackie, London

3. Huber GW, Iborra S, Corma A (2006) Chem Rev 106:4044

4. Zakzeski J, Bruijnincx PC, Jongerius AL, Weckhuysen BM (2010) Chem Rev 110:3552

5. Mohan D, Pittman CU, Steele PH (2006) Energy Fuels 20:848

6. Britt PF, Buchanan AC, Cooney MJ, Martineau DR (2000) J Org Chem 65:1376

7. Shabtai JS, Zmierczak WW, Chornet E, Johnson D (2003) USA Patent Application 972:461

8. Huber GW, Chheda JN, Barrett CJ, Dumesic JA (2005) Science 308:1446

9. Roma'n-Leshkov Y, Barrett CJ, Liu ZY, Dumesic JA (2007) Nature 447:982

10. Kunkes EL, Simonetti DA, West RM, Serrano-Ruiz JC, Gärtner CA, Dumesic JA (2008) Science 322:417

11. Zhao C, Kou Y, Lemonidou AA, Li XB, Lercher JA (2009) Angew Chem Int Ed Engl 48:3987

12. Hong DY, Miller SJ, Agrawal PK, Jones CW (2010) Chem Comm 46:1038

13. Zhu X, Mallison RG, Resasco DE (2010) Appl Catal A 379:172

14. Runnebaum RC, Nimmanwudipong $T$, Block DE, Gates $B C$ (2010) Catal Lett. doi:10.1007/s10562-010-0510-1

15. Bhore NA, Klein MT, Bischoff KB (1990) Ind Eng Chem Res 29:313

16. Bhore NA, Klein MT, Bischoff KB (1990) Chem Eng Sci 45:2109

17. Elliott DC, Hart TR (2009) Energy Fuels 23:631

18. Gutierrez A, Kaila RK, Honkela ML, Siloor R, Krause AOI (2009) Catal Today 147:239

19. Filley J, Roth C (1999) J Mol Catal A Chem 139:245

20. Popov A, Kondratieva E, Goupil JM, Mariey L, Bazin P, Gilson JP, Travert A, Mauge F (2010) J Phys Chem C 114:15661

21. Senol OI, Ryymin EM, Viljava TR, Krause AOI (2007) J Mol Catal A Chem 277:107 